\title{
"Stories of Montanistika" in the World of Virtual Reality
}

\author{
By Blaž Vrhovnik ${ }^{*}$, Śpela Klobučar ${ }^{ \pm}$, Petra Hrovat ${ }^{*}$,Zalka Leskovar ${ }^{+}$, \\ Martin Šip ${ }^{\S}$, Danej Brakič , Lucija Perovnik*, Boštjan Rožič**, \\ Matevž Novakं, Andrej Učakar, Petra Žvab Rožič * \& \\ Helena Gabrijelčič Tomc*
}

The main objective of the interdisciplinary research was a virtual reality (VR) interpretation of natural heritage, i.e., natural stones, that decorate the interior of the Montanistika building, which also houses the Department of Geology (Faculty of Natural Sciences and Engineering, University of Ljubljana). The aim of the study was to interpret and narrate stone heritage in 360 storytelling and VR. The VR solution was made for Oculus GO headgear. With a user centred approach for VR interactivity, VR gives the user an insight into the mysteries of the Montanistika building. 360-degree presentation of spaces contains information about geological characteristics of stones, their appearance and significance. Narration and screen play were designed considering individual premises of Montanistika building. 360 storytelling was implemented based on spatial orientation of the physical building and its premises. The result of the research is a VR solution that offers to the visitors a 360-degree experience, virtual and interactive walks through the building and learning about rocks from the presentation canvas. Moreover, the experience enables the immersion in the stories of Montanistika's stones and an attractive insight into the world of Slovene natural heritage.

Keywords: natural heritage, virtual reality (VR), interaction design, 360 storytelling, Montanistika building

\footnotetext{
"Undergraduate Student, Department of Textiles, Graphic Arts and Design, Faculty of Natural Sciences and Engineering, University of Ljubljana, Slovenia.

${ }^{ \pm}$Undergraduate Student, Department of Textiles, Graphic Arts and Design, Faculty of Natural Sciences and Engineering, University of Ljubljana, Slovenia.

"Undergraduate Student, Department of Textiles, Graphic Arts and Design, Faculty of Natural Sciences and Engineering, University of Ljubljana, Slovenia.

+Undergraduate Student, Department of Textiles, Graphic Arts and Design, Faculty of Natural Sciences and Engineering, University of Ljubljana, Slovenia.

${ }^{\S}$ Undergraduate Student, Department of Textiles, Graphic Arts and Design, Faculty of Natural Sciences and Engineering, University of Ljubljana, Slovenia.

'Undergraduate Student, Department of Textiles, Graphic Arts and Design, Faculty of Natural Sciences and Engineering, University of Ljubljana, Slovenia.

-Undergraduate Student, Department of Textiles, Graphic Arts and Design, Faculty of Natural Sciences and Engineering, University of Ljubljana, Slovenia.

${ }^{* * *}$ Professor, Department of Geology, Faculty of Natural Sciences and Engineering, University of Ljubljana, Slovenia.

'Researcher, Geological Survey of Slovenia, Slovenia.

${ }^{\circ} \mathrm{PhD}$ Student, Faculty of Natural Sciences and Engineering, University of Ljubljana, Slovenia.

^Associate Professor, Department of Geology, Faculty of Natural Sciences and Engineering, University of Ljubljana, Slovenia.

*Associate Professor, Department of Textiles, Graphic Arts and Design, Faculty of Natural Sciences and Engineering, University of Ljubljana, Slovenia.
} 


\section{Introduction}

The notion of inheritance is extremely broad and encompasses everything that previous generations have preserved for the present generation, and seems to be worthy of a larger share to be protected by our successors as well. Originally, the term heritage meant the legacy of the deceased, but later it was given various designations, such as cultural, natural, spiritual, archaeological etc. heritage. Today, very often the term heritage is first thought of as cultural or natural heritage (Jezernik 2005, Muršič 2005, Troha 2019).

In the Official Gazette of the Republic of Slovenia, the heritage is divided into material and living or intangible heritage; material heritage consists of movable and immovable heritage. Movable heritage is considered movable property or collections of movable property with heritage values. One of the types of tangible heritage is also stones and geological artefacts incorporated as a natural heritage in objects of cultural heritage (walls, furniture, buildings etc.) (ZVKD-1 2019).

Awareness of the importance of preserving heritage and its necessity for determining our identity emerged only in the modern age. Based on the preserved heritage, we can understand the development of past civilizations and, whether it is in terms of architecture, urbanism, live style, social and political organisation, customs, art and culture or any other area of heritage (Troha 2019).

A very big part in preserving the heritage has the UNESCO organization that emerged after the end of World War II to raise awareness of the importance of protecting cultural heritage (Žarnić 2012).

The digital preservation of cultural heritage is very important both from an educational and preventative point of view. One of the main motivations is certainly the protection against the dangers and risks to which cultural heritage goods are exposed. These threats can be of natural or socio-social origin. Natural impacts on the heritage can be long-term effects caused by weather and climatic factors, biological organisms, geological conditions and other stresses. Moreover, heritages can also be devastated by sudden natural disasters. Socio-social impacts include risks related to misconduct, wars, vandalism, wrong decisions, etc. (Žarnić 2012).

The digital preservation is of a great benefit for the museum collections in the form of an additional supportive presentation mode of heritage or even for virtual museums. Digital information (reconstructions and reproductions) is used as replicas intended either for exhibitions for the purpose of preserving originals, for the reconstruction of damaged objects or for the production of souvenirs. Often, cultural heritage originals are difficult to access or even inaccessible or removed from museums for a longer period due to restoration work. Such collections with geometric information and texture properties are therefore very convenient as they can be displayed or replaced in various ways and provide a quality and interesting alternative for educational purposes (Gomes et al. 2014, Pieraccini et al. 2001, Troha 2019).

Virtual Reality and Cultural Heritage 
Extended realities (XR), i.e., virtual reality - VR, augmented reality - AR, mixed reality - MR), etc., have completely found their worth in the virtual heritage field. These interactive technologies and presentative modes are strongly collaborative also with 3D technologies, web platforms, user interfaces, animations and computer (dynamic) simulations. As implementation of 3D technologies in cultural heritage also XR persistently gain attention of the researchers and the professionals. Some of the positive aspects of their usability are that with their constant development they are gaining accuracy and accessibility, they are reliable and non-invasive, and go hand in hand with sustainability. Moreover, XR solutions are attractive and they augment user experience (Ioannides and Quark 2014, Gabrijelčič Tomc et al. 2019).

In the museums and galleries the implementation of VR enables the heritage artefacts and objects to be better contextualized and multisensorial presented, they also provide an experiential space where personal and social experiences emerge in relation to artefacts. Virtual experience technology is also becoming more and more mature to facilitate learning about cultural heritage. We are increasingly moving away from traditional experiences where in a museum or gallery a visitor just watches an exhibition and is not fully engaged in the experience (Ch'ng et al. 2017a, Ch'ng et al. 2017b).

Paladini et al. (2019) demonstrated that the advantages of the implementation of VR in cultural heritage beside the attractiveness, simulation and perspicuity, is especially the effectiveness for observations of details of heritage objects, recognition of the materials and state of conservation. The VR presentations enable also the contribution to greater understanding of features and dimensions of objects of heritage. When VR content is presented in games, the interest for the heritage and the awareness about its preservation increase. Nevertheless, VR presentations benefit also research work and can be used as working and researching tool (approach), helping especially conservation experts. With the use of interactive technologies such as VR, there was a shift in the perception about the role of museums and galleries in the society and these spaces have opened up to a new audience. Technology and tourism are the key components in promoting this process. The trend is seen as an increase in the number of tourists seeking adventure, culture, history, archaeology and interaction with local people (Ulisa et al. 2015, Ozebek 2019, Digital meets Culture 2019).

One of the most successful projects for presenting cultural heritage through VR technology is the Rome Reborn project. From its beginnings, which included $3 \mathrm{D}$ reconstructions of the buildings of ancient Rome, the project has evolved into a truly interactive experience that takes the VR user into the world of ancient Rome. The process has been very broad and has been carried out through research work involving experts from different fields (architects, archaeologists, historians, 3D technologists, computer graphic designers, developers, etc.). Users of the free Roma Reborn VR app can immerse themselves in the ancient city, walk through the streets of the virtual city, enter buildings and experience the life of the inhabitants of ancient Rome while listening to the comments of renowned experts in archaeology and other fields (RomeReborn 2020). Inception is the project work 
of a large group of experts who have also developed this solution for the introduction of $3 \mathrm{D}$ technologies and $\mathrm{XR}$ in the field of cultural heritage by performing 3D reconstructions of cultural heritage artifacts, buildings, settlements and social environments of archeological or historical significance. The application that is originally aimed mainly at scientists, engineers and researchers in the field of 3D technologies, architecture, history, social sciences, etc., includes several modules and is also aimed at users of museums and galleries. The application includes sophisticated arithmetic solutions for the acquisition of 3D objects, the integration of geospatial information, includes both global and local positioning systems such as GIS, GPS, IPS etc., everything is assembled by modules into a complete solution with efficient functionalities and a user-friendly graphical interface. The Inception application also includes an interface for (VR in addition to $\mathrm{AR}$ and $\mathrm{MR}$ ), where 3D models of the architectural heritage and artifacts are accessible to all users (including vulnerable groups) in an attractive way, as well as to different hardware (Giulio et al. 2016, Maietti et al. 2018a, Maietti et al. 2018b, Karadimas 2019).

Research carried out by Shehade and Stylianou-Lambert (2020) revealed that professionals practice, experience and perceive the implementation of VR in the museums with seven categories of perceived advantages and nine categories of perceived challenges. One of the biggest challenges for VR technology is the social aspect, which is still marginalised in the solutions currently used in museums. Researchers in research invite developers and designers of VR solutions to focus more on this in the future: interactivity and social VR applications. The research also notes that there is still a lack of knowledge about these advanced technologies (use, benefits of use) among museum staff for successful use of VR technologies in museums, that there is a lack of high quality equipment and that the potential of these technologies and their use is insufficient, researched to ensure that it can be fully exploited in museum presentations.

The object of our project was the Montanistika building, which is the building of the Faculty of Natural Sciences and Engineering, one of the faculties of University of Ljubljana. From an architectural point of view, the Montanistika is a remarkable building and is inscribed in the register of cultural heritage. Although the building itself may not be the most original, its peculiarity is reflected in its inside construction, with imaginative and quality craft details in wood, wrought iron and stone. The interior decoration of the building with the natural stone emphasizes its monumentality, carries important information on the extraction and use of natural stone in the past and enables experienced and narrative learning of rocks. Various polished natural stones were used to decorate and construct certain elements, which emphasized the monumentality of the buildings.

The aim of the research was a presentation of geological material, i.e. natural stones that decorate the interior of the Montanistika building in an interactive educational presentation with 360-degree storytelling. The goal was to implement the VR solution that presents geological stories and according to user-centred design communicate about the Slovenian stone heritage. With the design of VR experience we planned to engage the participants that want to experience this 
building and the information about the stones in digital reality and the participants that cannot physically access the building and interact with it remotely.

\section{Experimental Part}

The methodology in the experimental part included the below listed phases that are presented in Figure 1:

- an overview of the geologically important rocks that make up the Montanist building;

- a selection of representative rocks for the virtual presentation, documenting and collecting information about rocks;

- user-centred planning and design (UCD) of VR application (strategy level, information architecture, wireframes)

- graphic and interaction design;

- 360 narration and screenplay design;

- content creation - planning, production and post-production (text writing, digital documentation and presentation of rocks, photographing, 360 video production);

- development of VR application in Unity;

- testing of VR application;

- exhibition of the final results at academic and national level.

Figure 1. Workflow

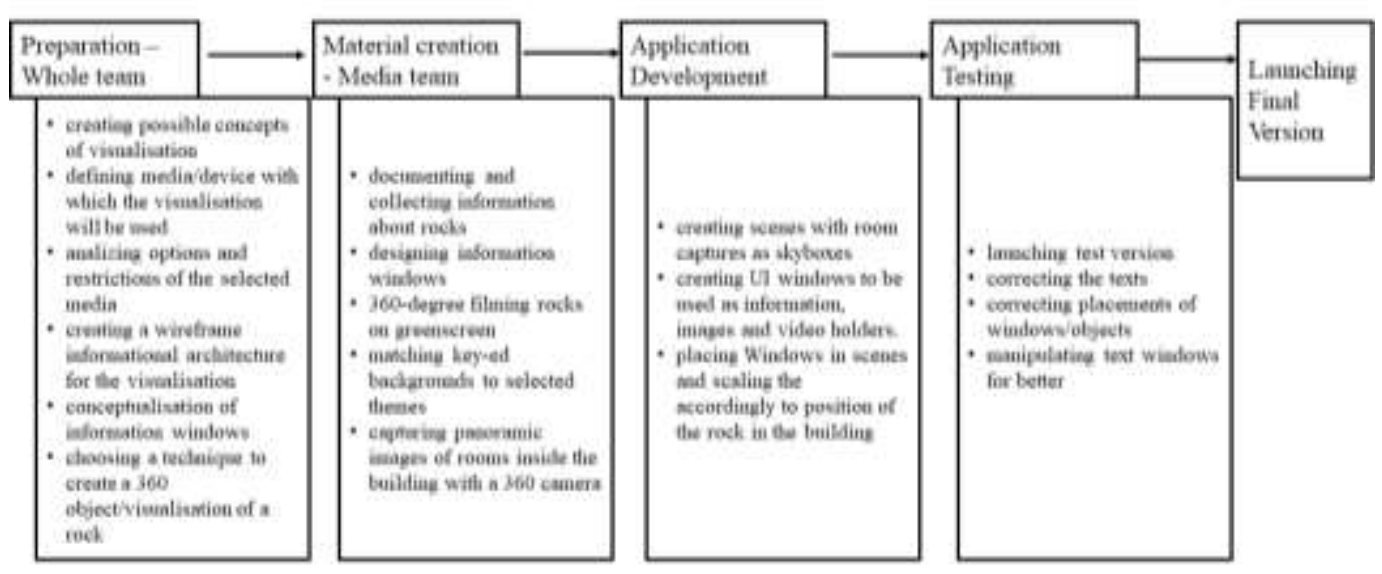

Stone Selection and Documentation

From a geological point of view, the hallways and lobby of the Montanistika represent a special geological museum, which thus combines natural and cultural heritage.

The interior of the building is decorated of mostly local architectural stones (Slovenian and Croatian) and two newly built foreign, but geologically interesting rocks (Figure 2). The rocks used are also interesting because they cover 
representatives of all three basic rock types and can thus be used as a tool in the presentation and teaching of geological content. Sedimentary rocks are represented by very diverse limestones, metamorphic marble, and some examples of intrusive igneous rocks. Interpretation and presentation are possible from several perspectives that give as the facts for narrative learning. The composition (minerals, fossils), color and other properties of rock describe the processes and environments of their formation, their architectural names can usually be linked to the excavation sites (locations of quarries), and the use can be compared with our own experience already seen. Such representations can lead to a greater degree of interest, understanding and knowledge sustainability.

Figure 2. Rock Decorations in the Walls, on the Floor and in the Stairs of Montanistika Building

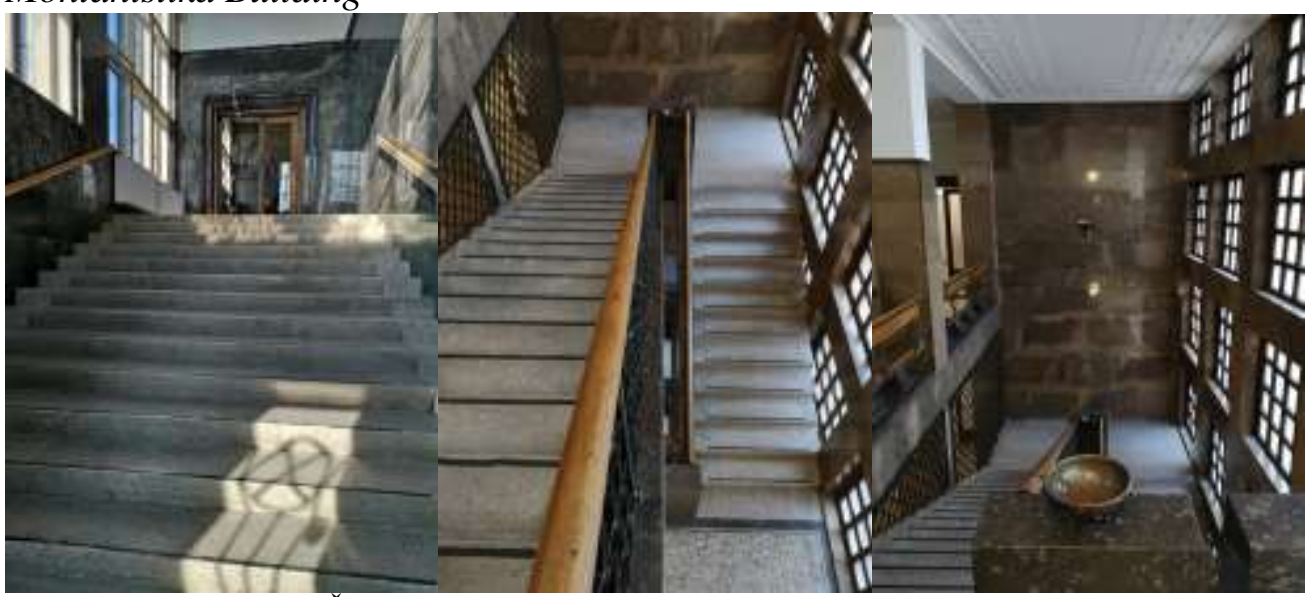

Source: Photos by Tina Živec.

\section{User-Centred Planning and Design}

VR solution was designed and implemented with the user-centred design (UCD) approach, which phases involved the definition of the strategy and the scope, designing the structure and skeleton level and in the last phase planning and developing the surface and sensory level of VR.

In strategy level target groups, needs and product objectives were defined. The partners in the process were the employees of the Department of Geology that is situated in Montanistika building. The problems to be solved with interactive solution were from the technical point of view digitalisation and preservation of natural heritage (stone walls) that is constructed in the interior of Montanistika and from the communicative and educational point of view promotion of and education about the building with the immersive technologies. Target groups included representative academia (students, teachers, researchers), visitors and tourists, and representatives of national institutions and cultural organisations (national Parliament, museums, galleries, etc.).

In scope level functional specifications and content requirements were defined. Functionalities were limited to VR touring. Defined content elements were: text descriptions with the explanation about the natural heritage, image elements with 
the facts about the stones, 360 recordings of the rooms and 360 recordings of representative stones.

In structure and skeleton level information architecture was defined that led to interaction and information design including development and design of 360 viewing and interaction of entering in the rooms.

Information structure (Figure 3) is showing the organisation, hierarchy and links between each part of VR solution. The user is guided through the VR solution via text boxes and subtle graphic elements. In each room user can see more information about specific rock he/she is observing via 360-degree photography/VR view and navigate with the clicks on small bluish buttons. In that way the user is presented with video, pictures and more information (item 1,2 and 3) about specific rock.

Figure 3. Information Architecture of VR Solution

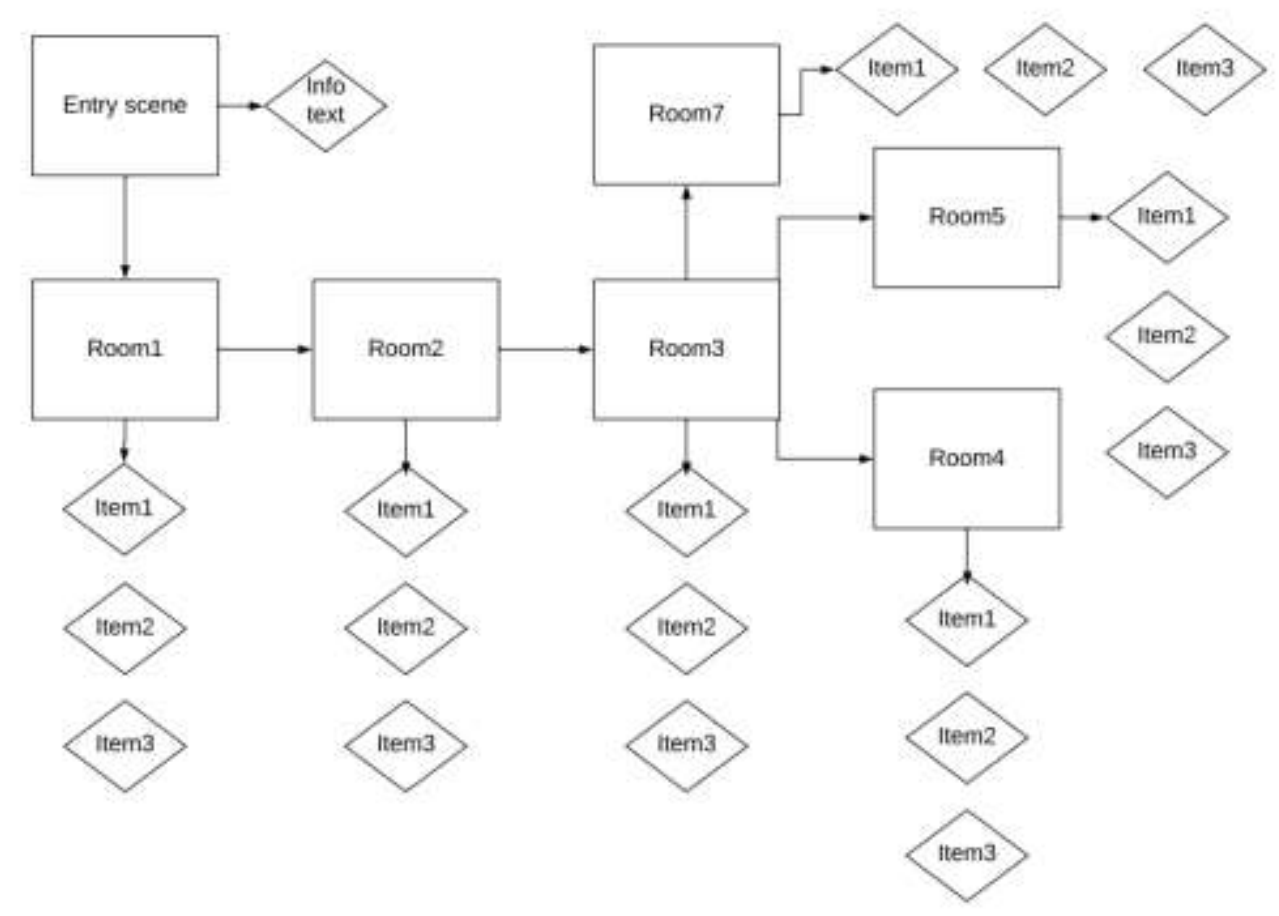

Last phase of UCD was the developing of surface and sensory level of VR with the colour pallet presented in Figure 4.

Colour scheme consists of four colours. Main colour is light yellow and is used for the main menu, neutral texts etc. Light blue represents sedimentary rocks, soft orange is for metamorphic rocks and light red for igneous rocks. The last three colours are used for video and text background when representing specific types of rocks. There is only one font used (in different sizes) and that is Liberation Sans. 
Figure 4. Colour Scheme of VR Solution

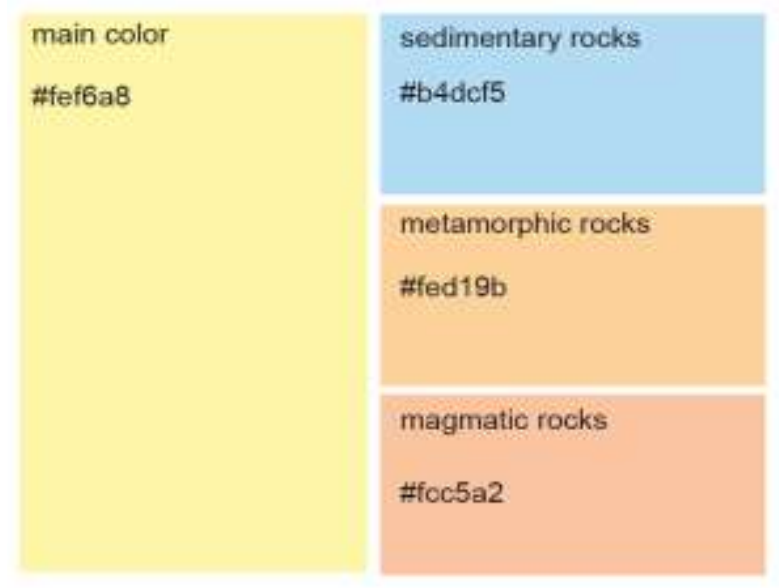

\section{$360^{\circ}$ Narration}

Wireframes of virtual reality were planned and designed along with a $360^{\circ}$ storytelling. Narration and screen play were designed considering individual premises of Montanistika building and planned participants' experience, i.e. immersion in the virtual Montanistika building and learning about information of stones, their origin and geological characteristics. 360-degree storytelling was implemented based on spatial orientation of the physical building and its premises (Figure 5). Content was prepared including geologically significant texts, graphic presentations, informative canvas, 360-degree video presentations of stones and premises of the building.

Figure 5. Planning of 360-Degree Storytelling

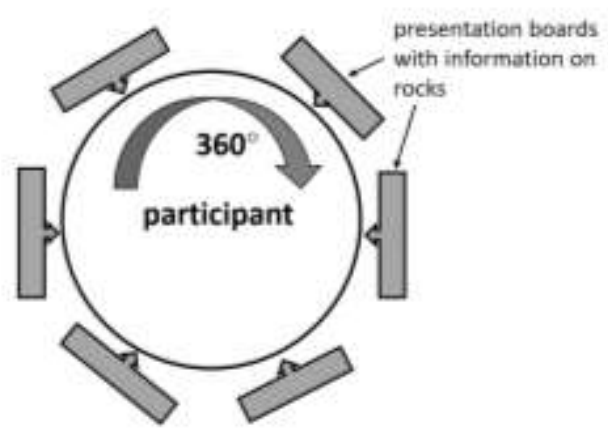

\section{Content Creation}

\section{Recordings of Stones}

The Department of Geology provided us with the samples of representative sedimentary, metamorphic and igneous rocks used as decoration in the building (Figure 6). We chose samples that, due to their form and characteristics, enable the presentation of various contents. Thus, leached fossils, weathered rock surfaces, 
samples with well-expressed characteristics were filmed. With these samples, we wanted to further visually present the geological content in the digital world.

\section{Figure 6. Selected Rocks}

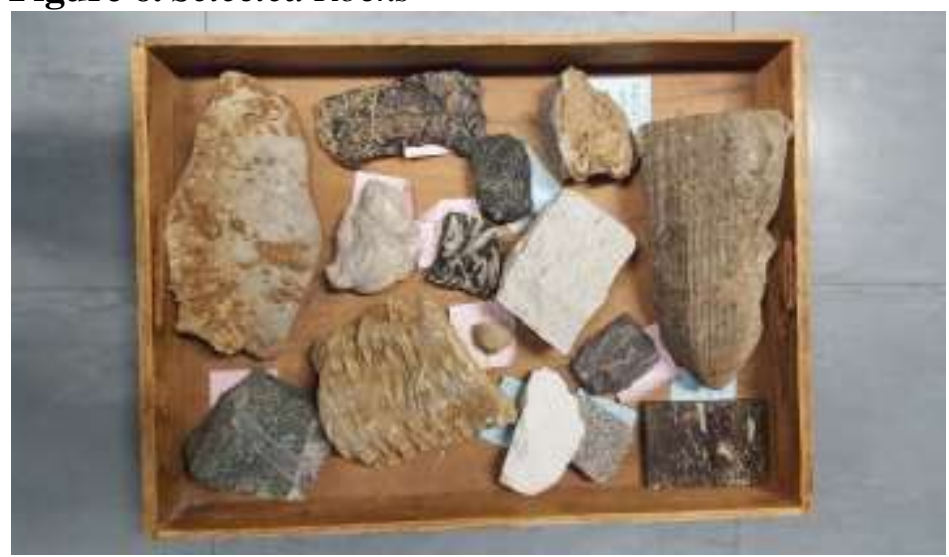

Presentation boards were designed to include 3D reproductions of rocks. Photogrammetry was excluded after preliminary experiments, as high-resolution polygon meshes of objects (rocks) would be needed to achieve sufficient reproduction quality, which would slow down the operation of the application for real-time use. Instead, the records of stones rotating in 360-degree took place in the photo studio, which allowed the appropriate fast and efficient rendering of stones from all angles. The stones were placed on the green screen and on the turntable that enable the recordings from different angles (Figure 7). Each stone sample was filmed, with camera Sony a7sii and Sony 24-70 2.8 lens, when rotated for 360-degree simultaneously.

Figure 7. Students during the 360-Degree Photography and Video Production with the Setting of the Green Screen and Recording Equipment

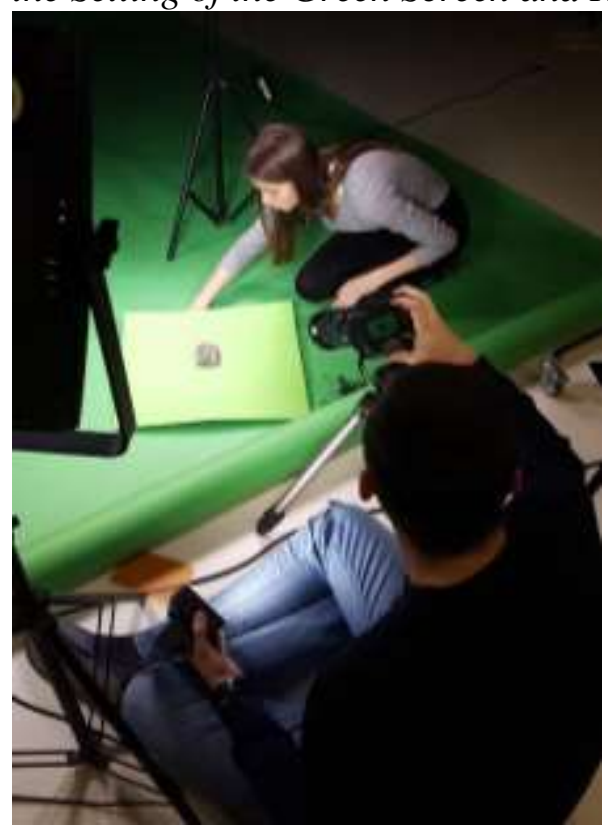


In post-production the green background of each rock was changed according to the colour scheme of the VR solution (sedimentary rocks blue, metamorphic rocks orange, igneous rocks red). The colour key effect needed to be used multiple times in order to change the colour of the background. The last step was exporting videos to loop when played. The results of the 360-degree recordings and 360degree video database are shown in Figure 8.

Figure 8. 360-degree Recordings of Rocks and 360-Degree Video Database
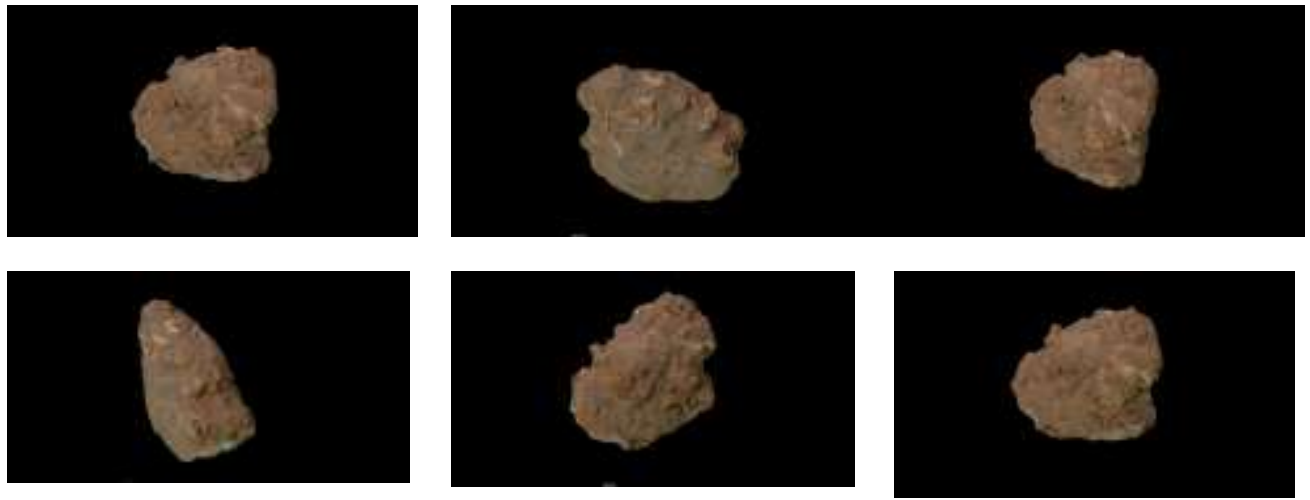

Weathered Limestone with Fossils
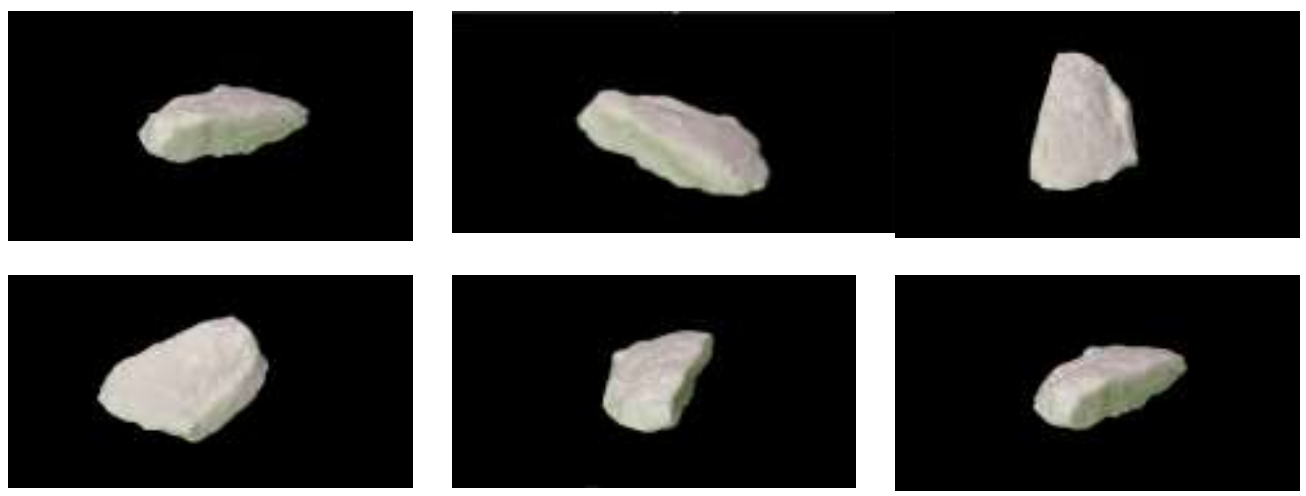

Marble 


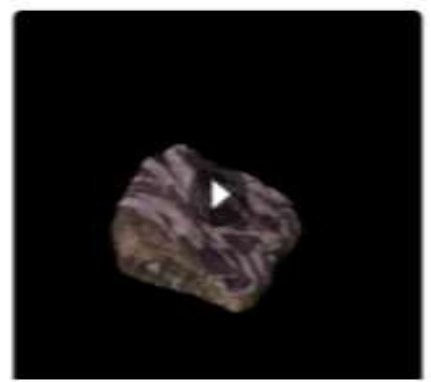

Eer $7 \operatorname{mot}$
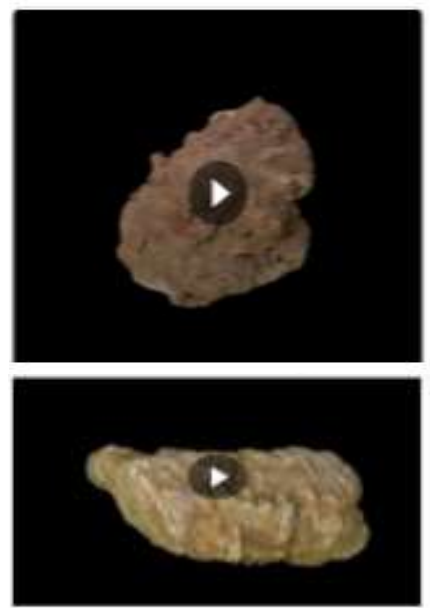

nerrimes

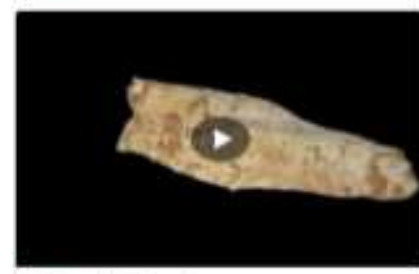

ail nerame

Database of All Rock Samples

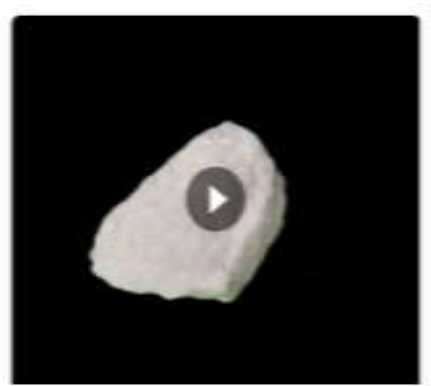

KeY 8 mo4
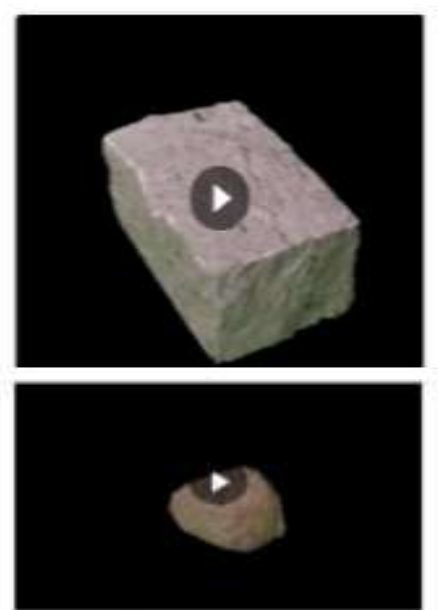

ingram

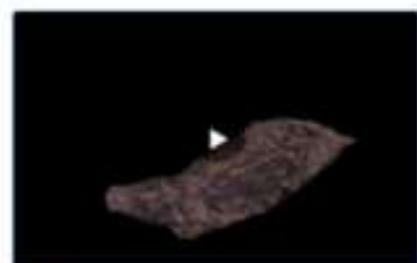

in wranes

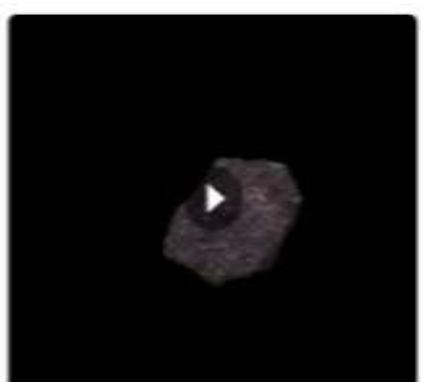

Ney $\operatorname{kermol}$
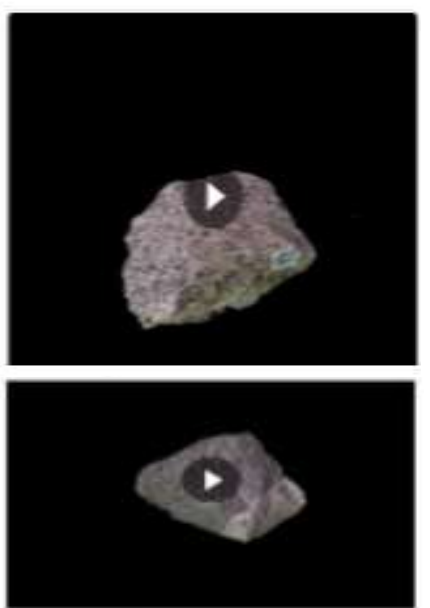

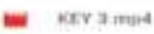

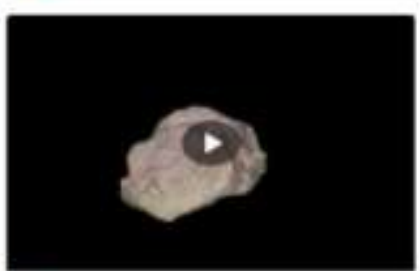

E rers $5 \operatorname{mog}$

\section{0-Degree Recordings of Building's Interiors}

For spherical images (Figure 9), a Ricoh Theta SC camera with two lenses was used. While shooting, it is important to keep in mind that when photographing it is necessary to pay attention to the light source. It can happen that the camera illuminates only one side of the image sensor, if it is pointing directly at the source. Consequently, the result can be an unevenly lit image. The images were processed in a photo editing software, where the visible parts of the camera stand were removed. 
Figure 9. Example of 360-degree Photo Sphere

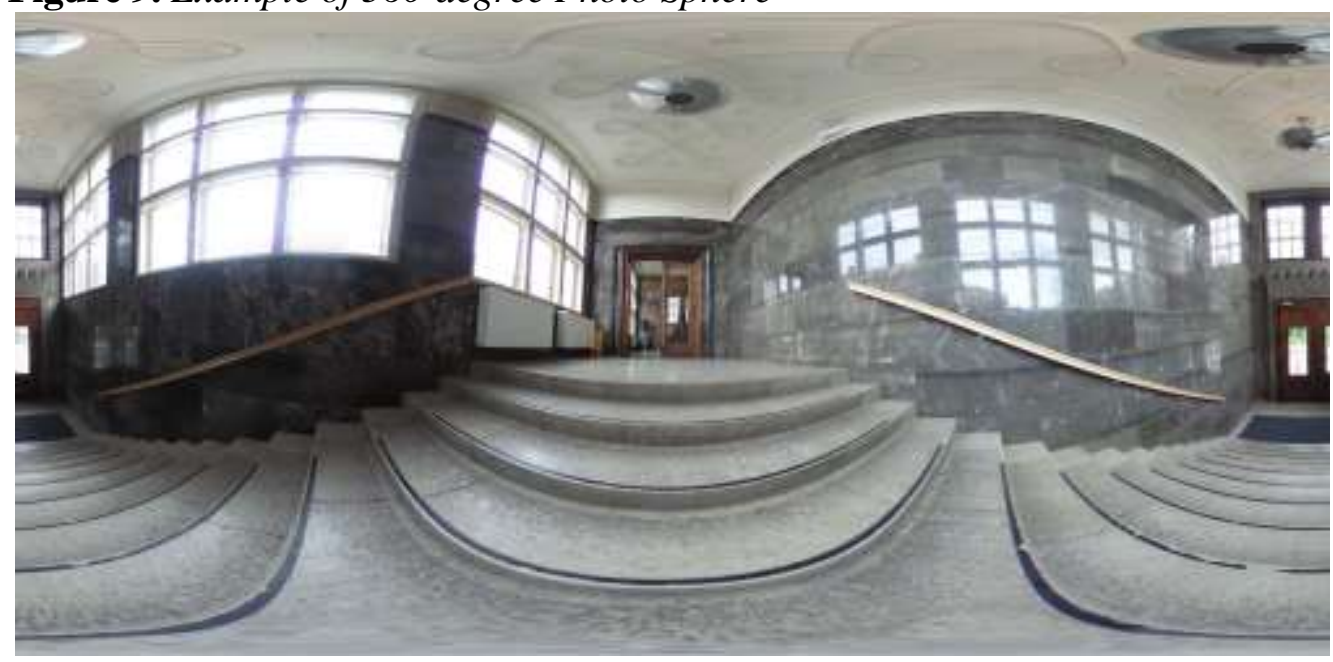

Development of VR Solution

For the development of VR solution, the chosen VR device was Oculus Go. We've chosen to work on open game and application development platform Unity in combination with Adobe Create Cloud. At first the idea was to develop using Unreal Engine due to its accessibility for VR, later on it has shown that Unity will serve better for our purpose due to bigger community support and free guides/tutorials for troubleshooting which we needed since none of us had any experience with developing a 3D application for android. Inside Unity workspace we've created a 3D project with final media Android VR.

Working environment or user interface (UI) layout in development consisted of 5 active windows (Figure 10) that allowed an effective workflow in Unity:

- Hierarchy - contains a file overview of every element in selected room (scene).

- Inspector - shows detailed information, which can be manipulated with either numerical values or tick boxes.

- Scene - is a 3D visualisation of the work environment where every element is displayed in the selected room.

- Project - contains a file explorer located in the projects folder on computer. It is mostly used to travel between scenes and add pre-made assets made in external software.

- Game - displays the 3D visualisation through the camera (user-controlled device) that allows the user to freely look around the room and interact with the object. Game window is in fact a simulation of what the user is seeing once he opens the VR application on his headset. 
Figure 10. Workflow, Working Environment and UI layout in Unity

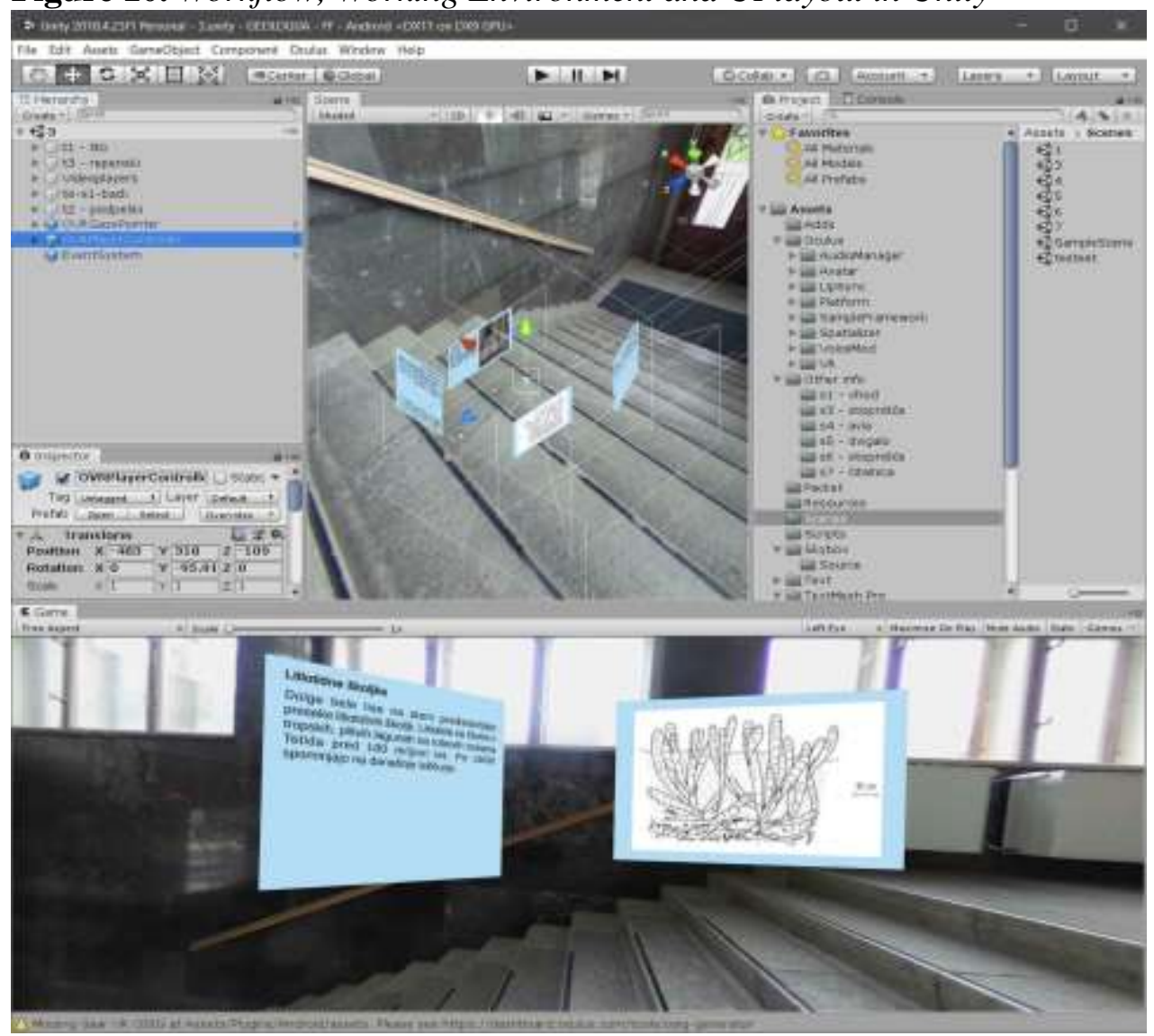

Developing the app required us to use 360-degree images as skyboxes and arrange them through the scenes according to information architecture. Additionally, to achieve the highest user immersion and application quality, the skybox setup requires some additional manipulations to remove seams done at image border merging.

Inside the scenes we have used text, photographs and videos. That material was used inside the user interface on so-called 2D canvases arranged through the user's 3D worldspace (Figure 11). When placing the canvases forced perspective came into use to achieve perceived distance between user camera, buttons, text and other visual media. That was used since if an object is too far from the player camera, at certain view-angles the content becomes cut out of the view area, as the camera renders only what it sees, and we get loose user immersion. Canvases also include "keyed" 360-degree recordings of stones through rendered texture function since the video playback requires real-time rendering and not just a static image texture. 
Figure 11. Placement of Information inside the $2 D$ Canvases

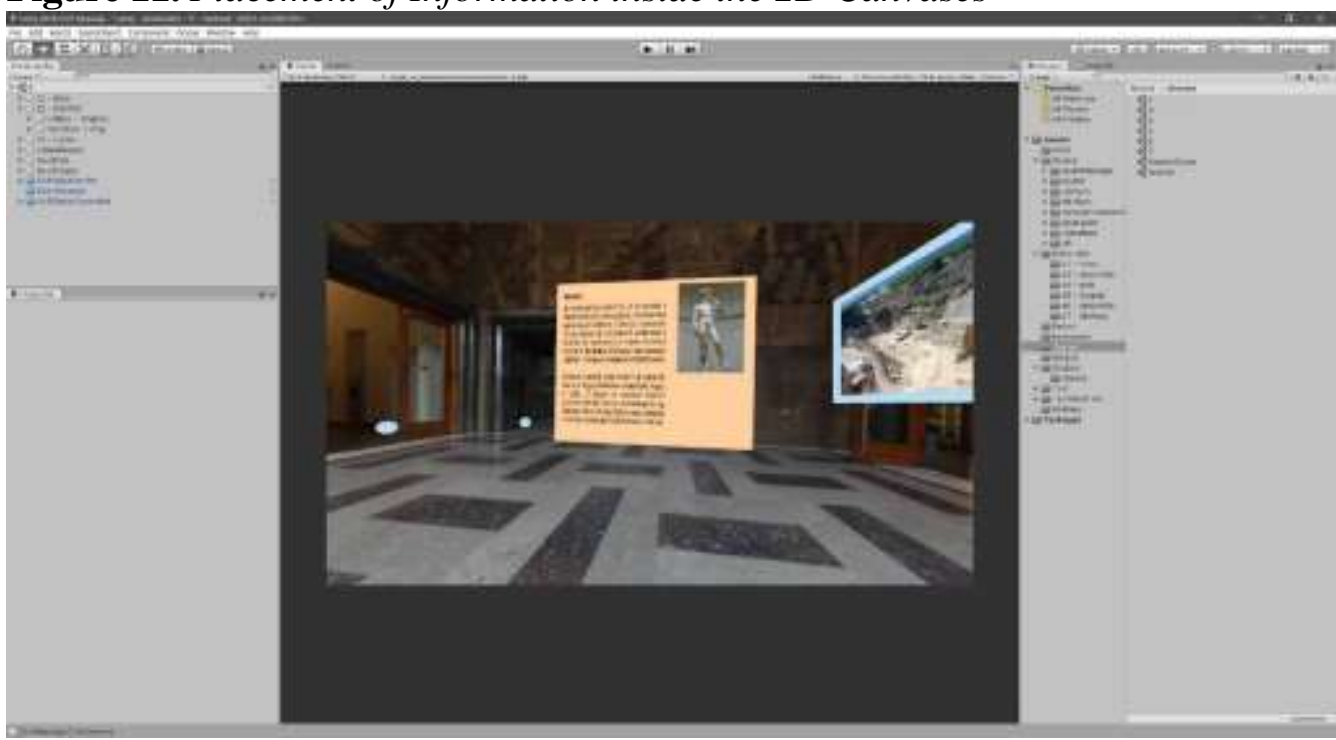

After the scenes were finished, we had to arrange movement (through buttons) according to information architecture and setup the controller with which the user views the rooms and move among them. Figure 12 presents placement of visual content inside of 360-degree panoramic shots inside Unity.

Figure 12. Placement of Content Inside 360-Degree Panoramic Shot Skyboxes with user Camera
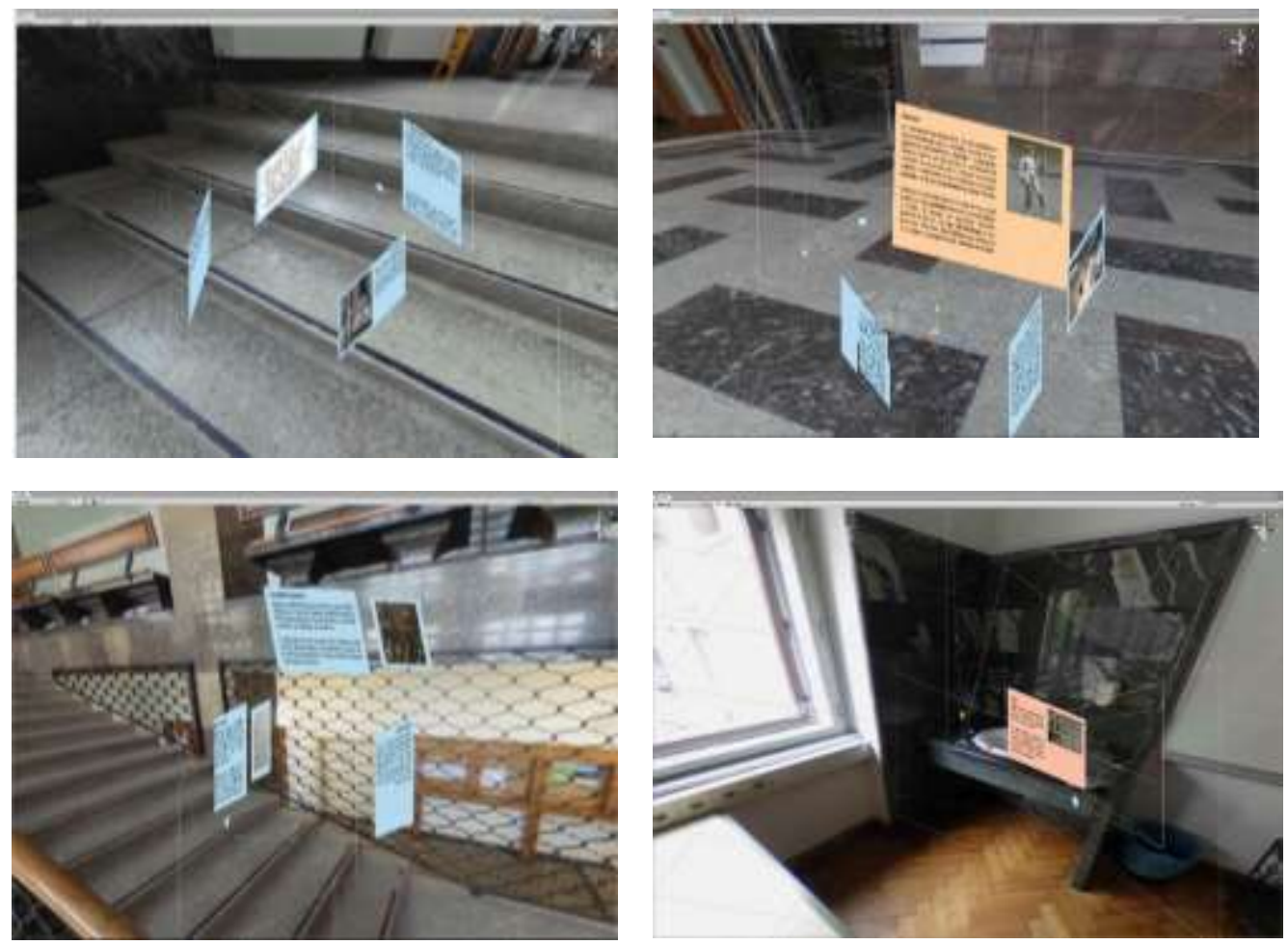
With the final VR reality settings, it was necessary to perform several testing phases, which enabled the correction of technical and performance errors such as cutting, button unresponsiveness, layout optimization, text styles and the use of more appropriate image content.

\section{Results and Discussion}

From the research and project work and on the basis of the results of a 360degree digital representation and interpretation of the Montanistika building and the digital reproduction of representative stones, we can draw some essential insights which can serve as recommendations for further work.

We found that content creation for 360-degree media and VR environment is different from content creation for other media (especially when compared to media played on flat screens). The texts, as are shown in Figure 13, should be short and concise (even shorter than for traditional digital and interactive media). 3D elements must be perfected from all angles. The photos must be placed and arranged in a 360-degree space according to the participant's movement and experience, so that the target and the sequence attract the attention. Navigation must be simple (see navigation buttons in Figure 13), but still take the participant's sensory perception fully into account, as the user must know at all times (space) how he or she got into this space and where to go from this space.

For the 360-degree narrative, we found it challenging both in terms of preproduction and content production. In our case, however, postproduction was less demanding (mainly due to the use of 360-degree footage). In pre-production, it proved to be very important to plan the management of the virtual reality participant, i.e. how to guide him or her through the specific room and between rooms with the content displayed on the presentation boards, so that the experience is satisfying, pleasant and educational for the user. With the increase in the number of content types (video, graphics, text) and interactivity (transitions between rooms, interactive content), the complexity of planning increases even further. In addition, the number and complexity of the content elements should be adapted to the entire virtual environment, as shown in Figure 13, by displaying the graphic elements (presentation boards) on the 360-degree background in a meaningful way.

During production, we realised that the quality of the 360-degree camera shots is crucial, for which it is best to shoot in at least $4 \mathrm{~K}$ or even $8 \mathrm{~K}$ quality. We did not use this quality, so the background of the Montanistika was shot with a slightly lower resolution. A higher 360-degree video resolution would result in higher quality virtual rooms of Montanistika, but this would complicate the process of post-production and video processing in the Unity platform.

Furthermore, the Unity platform has proven to be a highly credible set of techniques and tools to achieve results when implementing different types of content in 360 space. Despite the fact that it was the first time that the students met with both 360-degree content production and virtual reality, they acquired enough knowledge in a relatively short time (one semester) to implement a planned virtual 
environment in Unity with interactivity, attractive content and consequently an optimal user experience.

Figure 13 presents final scenes and stories of Montanistika in the VR environment.

The final VR experience comprises 7 scenes (6 rooms and the entry scene) and covers all the important information about natural stone in the building. Different types of content presentations placed on the real scenes of the building allow the user the experience of geological stories of the natural stone of Montanistika in the virtual world. With VR experience the natural heritage of the building, which is usually hidden, is now visible and accessible from the general public (also vulnerable ones). Besides, the geological contents are presented interactively and experienced also outside the building which enriches the learning of geology. In the workflow the user-centred design was implemented that was found to be a valuable methodology for the effectiveness, usefulness and likeability of the VR solution and learnability about the heritage of Slovenian stones. VR presentation that includes Stories of Montaniatika was presented to the audience as part of the main project event European Researchers Night in September 2019, a pan-European project aimed at bringing research work closer to the general public. With a strong emphasis on the impact and importance of research in everyday life, it encompasses many smaller events (also project named Humanities Rocks!) that enable researchers to present their research work and innovation.

The audience accepted the VR solution enthusiastically and rated the experience as a perfect upgrade to a physical walking through Montanistika building. In addition, the developers were offered some further research opportunities in terms of implementing VR technologies on other buildings of national importance, which also include the heritage of stones in interiors or exteriors.

Figure 13. Final Scenes and Stories of Montanistika in the VR Environment

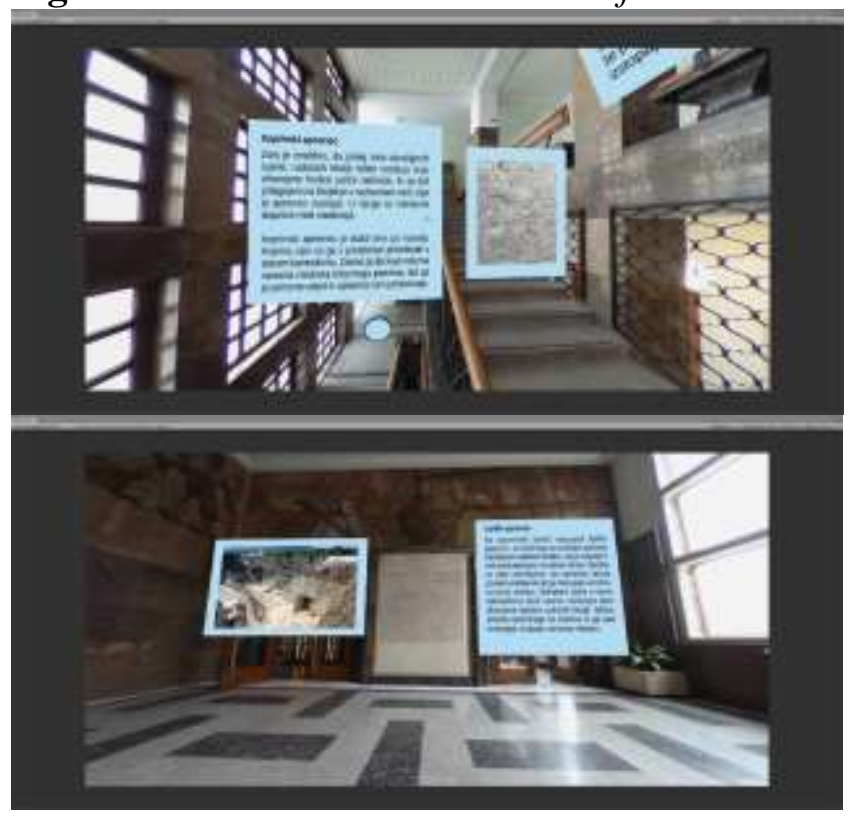




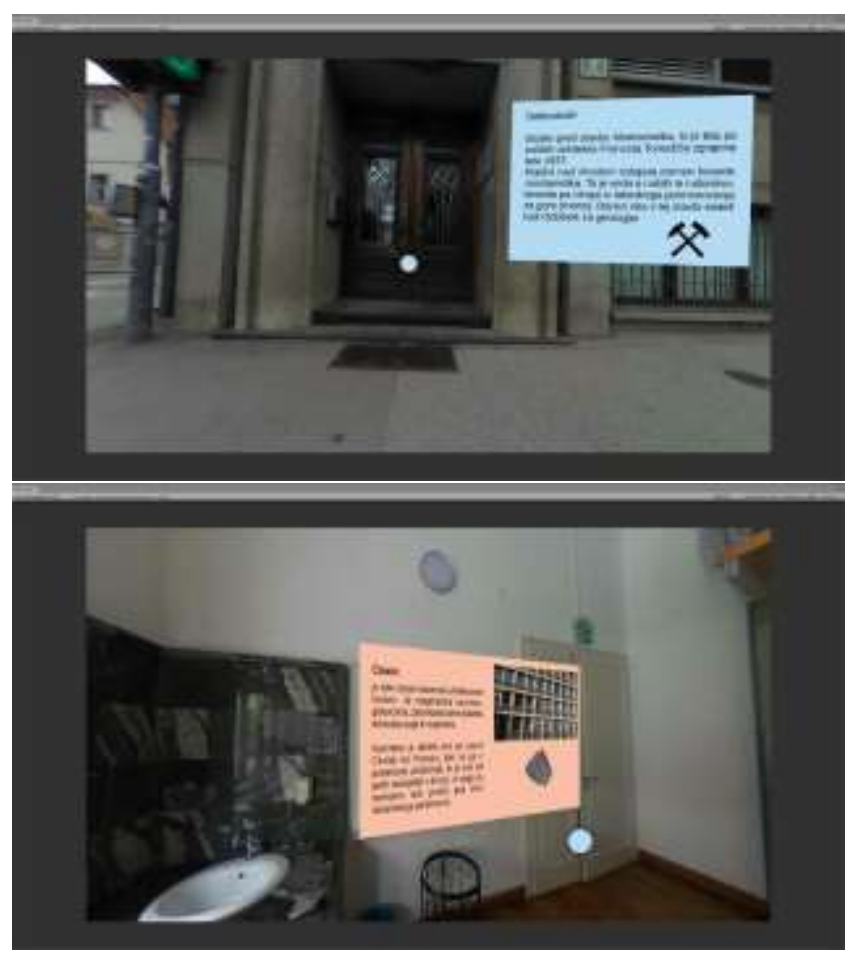

\section{Conclusion}

The results of this research prove that a 360-degree virtual representation of a Montanistika building is a rich immersive experience of the architecture of the building's interior and the natural heritage and thus the stones for the participants.

Workflow definition, design and development of the presented VR solution was also evaluated in terms of a starting point for further improvements. The project was performed by the students of graphic design and interactive communication, who during this project first encountered this type of technology. It is estimated that major upgrades to the solution could be carried out at the level of interactivity and use of different VR device, which would include besides the transitions between Montanistika rooms, additional interactions of experiencing rocks (interactive virtual rotation, etc.). In addition, we believe that the implementation of the audio narrative would increase the accessibility. However, the results of the research and development of VR Stories of Montanistika with the contents of natural heritage of rocks are in Slovenia the first example of the exceptional value of these technologies for digital preservation, presentation and, nevertheless, considering the geological value, a greater recognition of Slovenian stones in architecture.

In the current process of upgrading the presented results is the translation of content into English and the transfer of the solution to the social network YouTube. By including this social network as a communication channel, the presentation of the Montanistika building and the natural heritage of the stones stored in it will be accessible to a wider audience. In this way we will include a very influential contact point in the digital strategy of the VR solution, on the basis 
of which it will be easier to achieve the goal of spreading the recognition of Slovenian architectural heritage and the use of VR technology.

\section{References}

Ch'ng E, Cai Y, Thwaites H (2017a) Introduction, presence: teleoperators and virtual environments. Special Issue on VR for Culture and Heritage: The Experience of Cultural Heritage with Virtual Reality 26(3): III-VI.

Ch'ng E, Cai Y, Thwaites H (2017b) Special issue on VR for culture and heritage: the experience of cultural heritage with virtual reality, teleoperators and virtual environments. Massachusetts Institute of Technology 26(3): iii-vi.

Digital Meets Culture. Virtual reality. Retrieved from: https://www.digitalmeetsculture. net/tag/virtual-reality/. [Accessed 28 July 2020.]

Gabrijelčič Tome H, Kočevar TN, Škerjanc A, Pivar M (2019) Študija oblačil na primeru 3D interpretacije Plečnikovega spomenika, posvečenega vojskovodji Janu Žižki. (Study of clothing using the example of 3D interpretation of Plečnik's monument dedicated to military commander Jan Žižka). In N Cvikl, M Hren Brvar (eds.), Tekstil, Oblačilna Kultura in Moda: The Collected Volume of the Symposium, October 2019, (Zbirka Museoeurope, 6). Maribor: Pokrajinski Muzej, 43-50.

Gomes L, Pereira Bellon OR, Silva L (2014) 3D reconstruction methods for digital preservation of cultural heritage: a survey. Pattern Recognition Letters 50(Dec): 3-14.

Giulio Di R, Maietti F, Piaia E (2016) 3D documentation and semantic aware representation of cultural heritage: the INCEPTION project. In CE Catalano, L De Luca (eds.), EUROGRAPHICS Workshop on Graphics and Cultural Heritage, 195198.

Ioannides M, Quark E (2014) 3D research challenges in cultural heritage: a roadmap in digital heritage preservation. Berlin Heidelberg: Springer-Verlag.

Jezernik B (2005) Preteklost in dediščina. (Past and heritage). In Heritage in the Eyes of Science). In J Hudales, N. Visočnik (eds.), Dediščina $v$ očeh znanosti, 11-24. Ljubljana: Univerza v Ljubljani, Filozofska fakulteta, Oddelek za etnologijo in kulturno antropologijo.

Karadimas D, Somakos L, Bakalbasis D, Prassas A, Adamopoulou K, Karadimas G (2019) Current and potential applications of AR/VR technologies in cultural heritage. INCEPTION virtual museum HAMH: a use case on BIM and AR/VR modelling for the historical archive museum of Hydra Greece. In A Moropoulou, M Korres, A Georgopoulos, C Spyrakos, C Mouzakis (eds.), Transdisciplinary Multispectral Modeling and Cooperation for the Preservation of Cultural Heritage. TMM_CH 2018. Communications in Computer and Information Science 962. Cham: Springer.

Maietti F, Giulio Di R, Piaia E, Marco M, Federico F (2018a) Enhancing heritage fruition through 3D semantic modelling and digital tools: the INCEPTION project. In IOP Conference Series: Materials Science and Engineering 364. Florence, Italy: HeriTech - The Future of Heritage Science and Technologies, IOP Publishing Ltd., 1618.

Maietti F, Piaia E, Mincolelli G, Di Giulio, Imbesi RS, Marchi M et al. (2018b). Accessing and understanding cultural heritage through users experience within the INCEPTION project. In M Ioannides et al. (eds.), Digital Heritage. Progress in Cultural Heritage: Documentation, Preservation, and Protection. EuroMed 2018. Lecture Notes in Computer Science 11196. Cham: Springer. 
Muršič R (2005) Uvod: h kritiki ideologije dediščinstva ter slepega enačenja znanosti in stroke. (Introduction: to the critique of the ideology of heritage and the blind equation of science and profession). In J Hudales, N Visočnik (eds.), Dediščina v očeh znanosti, 7-10. Ljubljana: Univerza v Ljubljani, Filozofska fakulteta, Oddelek za etnologijo in kulturno antropologijo.

Ozebek K (2019) Poustvaritev 3D-modela rimskega domusa v virtualni resničnosti. (Recreation of Roman Domus 3D model in virtual reality). Master Thesis. Ljubljana, Slovenia: University of Ljubljana.

Paladini A, Dhanda A, Reina Ortiz M, Weigert A, Nofal E, Min A et al. (2019) Impact of virtual reality experience on accessibility of cultural heritage. The International Archives of the Photogrammetry, Remote Sensing and Spatial Information Sciences XLII-2/W11, Geores $2019-2^{\text {nd }}$ International Conference of Geomatics and Restoration, May 2019, Milan, Italy.

Pieraccini M, Guidi G, Atzeni C (2001) 3D digitizing of cultural heritage. Journal of Cultural Heritage 2(1): 63-70.

RomeReborn (2020) Retrieved from: https://www.romereborn.org/. [Accessed 28 July 2020.]

Shehade M, Theopisti Stylianou-Lambert T (2020) Virtual realities in museums: exploring the experience of museum professionals. Applied Sciences 10(11): 4031-4051.

Troha N (2019) 3D dokumentiranje in interpretacija počivalnika Gondola. (3D documentation and interpretation of lounger Gondola). Master Thesis. Ljubljana, Slovenia: University of Ljubljana.

Ulisa A, De Paolis LT, Tutberidze M (2015) Virtualization of digitalized cultural heritage and use case scenario. Procedia Computer Science 77(2015): 199-206.

Zakon o varstvu kulturne dediščine (ZVKD-1) (2019) Uradni list Republike Slovenije No. 16/2008. (Official Gazette of the Republic of Slovenia No. 16/2008). Retrieved from: https://www.uradni-list.si/glasilo-uradni-list-rs/vsebina/2008-01-0485?sop=2008-010485. [Accessed 30 July 2020.]

Žarnić R, Rajčić V, Moropoulou A (2012) Identity card of cultural heritage: how to collect and organize data. In M Ioannides, D Fritsch, J Leissner, R Davies, F Remondino, R Caffo (eds.), Progress in cultural heritage preservation. Limassol: Springer, 340-348. 
